\title{
Using Chat Rooms in a Plant Nutrition Course: Bane or Boon?
}

\author{
Ellen T. Paparozzi ${ }^{1}$ and Kimberly A. Williams ${ }^{2}$
}

\begin{abstract}
AdDITIONAL INDEX WORDs. distance education, two-way compressed video, Web CT
Summary. Chat rooms and their use in everyday life are becoming increasingly common, and the technology may be a useful tool to link students with experts of a given subject material and each other. In our shared course Plant $\mathrm{N}$ utrition and $\mathrm{N}$ utrient $\mathrm{M}$ anagement, we experimented with using a chat room to link students with experts in the field of plant nutrition. 0 ur main goal was to enhance the learning experience of the students by providing them with access to national and international plant nutrition researchers. Web CT was used to create and conduct the chat rooms and a chat etiquette evolved to prevent crosstalk and control the flow of the discussions. Positive outcomes of the chat room use included exposure of students to the technology and beneficial interaction between students and experts. N egative aspects of chat room use included the time involved to coordinate the overall effort and train experts to use the technology; the slow pace of some chats; effective grading; and the superficial coverage of some topics. We are developing modifications for future sessions to allow subjects to be explored in more depth and to improve networking between students and experts.
\end{abstract}

nternet chat rooms provide social and technical information and interaction to the computer-literate of any age (Betzold, 1998; $\mathrm{H}$ eid, 1998; Jackson, et al., 1996). Weekly chat rooms linking our upper division undergraduate and graduate students with national and international plant nutrition experts in horticulture and agronomy were an integral part of a newly created course in Plant $\mathrm{N}$ utrition and $\mathrm{N}$ utrient $\mathrm{M}$ anagement. The course was taught via synchronous twoway video conferencing between the $U$ niversity of $\mathrm{N}$ ebraska-Lincoln ( U N L) and Kansas State U niversity (KSU) as two 75-min lectures each week. A total of 13 students participated in the initial course offering with 1 undergraduate student and 12 graduate students. Ten of the graduate students were from $\mathrm{UN} \mathrm{L}$ and the other 3 students were from KSU. A chat room motif was selected over a bulletin board or online forum to allow for succinct, real time interactivity between student and expert (Pritchard, 1998). O ur main goal was to enhance the learning experience of the students by providing them with access to national and international plant nutrition researchers.

Course development was supported by a challenge grant from the U SDA H igher Education Programs. This manuscript has been assigned J ournal Series N 0. 001-2, College of Agricultural Sciences and N atural Resources, U niversity of N ebraska and C ontribution no. 00-80-J from the Kansas Agricultural Experiment Station. The cost of publishing this paper was defrayed in part by the payment of page charges. U nder postal regulations, this paper must therefore be hereby marked advertisement solely to indicate this fact.

${ }^{1}$ D epartment of H orticulture, U niversity of N ebraska-L incoln, Lincoln, NE 68583-0724.

${ }^{2} \mathrm{D}$ epartment of $\mathrm{H}$ orticulture, Forestry and Recreation Resources, Kansas State U niversity, M anhattan, KS 66506-5506. 


\section{Methods}

The web template chosen for this course was Web CT (U N L, Lincoln, N eb.). Access to this entire site is controlled by password. A secured chat room is one of many features within a Web CT site and the security was desired to prevent lurking of uninvited hackers. The chat topics and experts were chosen based on subject material presented in the course that the instructors felt would benefit from either additional coverage by an expert (e.g., mycorrhizae) or topics from the lecture that needed to be integrated into current research usage (e.g., use of geographic information systems (GIS) in plant nutrient management). A total of 10 chat sessions wereled by various experts in the field of plant nutrition. Five experts were horticultural faculty members and five were agronomy faculty members with two international expertsfrom Puerto Rico and Guatemala.

The chat session ran for $1 \mathrm{~h}$ outside of class time (8:00 PM on Wednesday evenings) and experts, students, and instructors could access the chat room from university facilities or home. In addition to the training sessions held earlier for the experts, the first chat session was designed to introduce studentsto chat room technology (e.g., logging on and off, sizing windows, etc.) and the chat eti- quette. Students were then asked to select topics for which they would like to be the session moderator. The student moderators were to contact the expert via e-mail in advance of the session and request readings related to the session for the entire class. Student moderators as well as the other class members were to have questions ready. After every session, logs of the chat room session were printed out and made available to the students for review. Students were graded based on participation, which included number of times they served as a moderator and number of questionsthey asked. A pre-course survey wasadministered to establish students' comfort level and experience with the various technologies, including chat rooms. Thechat room was evaluated by the students at the mid and end of the course, and the chat experts provided feedback about their experience at the end of the course.

Thechat etiquette controlled the flow of the discussion and was instituted to prevent cross talk and chaos during the chat sessions. Some of the basic principles were that students would only ask a question or comment when they were recognized by the student moderator or chat expert, and they would indicate that they would like to contribute by typing a "?" (to ask a question) or " $\mathrm{C}$ " (to make a comment) into the dialogue. When

\section{Fig. 1. Excerpt from a synchronous chat session on the topic of soluble salt management during container production.}

Student moderator: Go ahead, [student 1].

Student 1: I sthere something that can be injected into the water before irrigating in order to decrease the soluble salts level?

Chat expert: Yes. There are a lot of things we can do, depending on the specific salt problem.

Student 2: ?

Student 3: C

Chat expert: We can inject acid to remove the bicarbonates and carbonates, which is a practice that is now routine in Texas and across the U.S.

Chat expert: We can inject polyphosphates to remove iron, or use injected aeration.

Chat expert: We can remove $\mathrm{N}$ a with a $\mathrm{K}$-charge water softener.

Chat expert: But if we want to decrease total salts, the only option is reverse osmosis water purification, which is quite expensive.

Chat expert: All the other methods I told you about were just swapping one salt for another, i.e. a less harmful salt for a more harmful salt. D one.

Student moderator: Go ahead, [student 3].

Student 3: O ne method of decreasing the content of irrigation water is to blend waters from different sources (e.g., wells).

Student 3: thereby diluting the salt concentration by using water which contains either lower electrical conductivity

Student 3: or water of a lower concentration of the toxic ion. Done.

Chat expert: We routinely blend water of different sources, if a better one is available, and we al ways blend R.O. water with tap water. D one.

Student moderator: You're up, [student 2].

Student 2: What are the physiological effects of high soluble salts other than toxicity?

Chat expert: Gosh [student2], that sounds like an exam question-will I be graded?

Student 2: $N$ ot by me.

Chat expert: Good question. 1) competition between ions for absorption site during uptake and sometimes physiologically inside.

Chat expert: Ex., $\mathrm{N}$ a can substitute for $\mathrm{K}$ in many reactions, but if too high masks over $\mathrm{K}$.

Chat expert: 2) major effects on membrane integrity and semipermeability.

Chat expert: Salinity induced membrane leakage is a major problem, and actually a good way to quantify salinity damage. Chat expert: Fortunately, some of the "big" processes, i.e., photosynthesis and respiration, are quite resistant. D one. 
any participant (student or expert) was finished with their statement(s), they would type "done" (Fig. 1).

\section{Results}

On the positive side, students enjoyed using the chat room as a learning tool. Their comfort with this technologyincreased substantially with a mean score increase of 1.18 between the precourse and end of course survey (scale range of $1=$ not at all comfortable to 5 = very comfortable). Eight-five percent of students agreed or strongly agreed that the training given at the first chat session wasnecessary/ useful. Studentsparticularly enjoyed being the moderator, and commented that they learned a lot and that being moderator gives organization and leadership responsibility. They liked the chat room etiquette as it succeeded in preventing crosstalk, but they wanted the chat to move faster. Students mentioned that if they accessed the chat room in pairs or groups rather than alone, they were able to use the lag time to discuss the topic among themselves and create questions. There was a definite preference for certain topics over others and students liked topics that related to previously covered lecturematerial and, not surprisingly, their own areas of study.

Students were divided on whether or not they were intimidated to ask questions as a member of the chat audience. Comments included "it is better to keep your mouth shut and let people think you are stupid than type a question and let them know" versus "it is very impersonal and easier to ask questions" and "the environment allows us to be comfortable enough and not be intimidated to ask questions." International students in particular felt hin- dered bytheneed to typetheir dialogue. On the negative side, coordinating a chat room requires investment of extra time on the part of the instructors. This extra time was particularly true as most of the experts had never visited a chat room and needed one or more training sessions, as well as visiting an ongoing chat, before they felt comfortable in their role. Experts also provided references related to their chat and interacted with student moderators, thus, making asubstantial time commitment.

Fifty-four percent of students agreed or strongly agreed that the chat rooms were a waste of my time. Additionally, the instructors were dissatisfied with the grading scheme and the superficial coverage of topics. A number of chat experts were disappointed with the apparent inadequate preparation on the part of the students for their chat session, and in fact, only $46 \%$ of students agreed or strongly agreed that they " prepared thoroughly for the chat sessions by reading the pre-chat readings assigned by the chat leader." Finally, there were unexpected and unnecessary technology problems.

\section{Conclusions}

Through the experience of the first course offering, key goals of futurechat room use haveevolved. These goals are to 1) provide opportunities for students to network with experts beyond the boundaries of their own institution and become comfortable entering into dialog with other experts; 2) increase the depth of knowledge to which the students are exposed and by which they are challenged; and 3) involve students in discussions of controversial topics where even experts disagree on what the facts mean. To improve the use of the chat room as a learning tool, several modifications are being considered for the next course offering to increase the depth rather than breadth of topic content and networking with experts.

Changes will include fewer chat sessions; we proposefour sessions with experts (plus one introductory session) where the whole class is present in one room at each institution. $U$ se of a threaded discussion or online forum before and/ or after the synchronous chat will allow students prolonged interaction with the expert on the assigned readings and may increase the depth of topic coverage. A different grading scheme will be used, such as a homework assignment and/ or exam questions specifically related to the chat session to increase student responsibility for subject material covered. Finally, wewill offer the synchronouschat session in an earlier or different timeslot, depending on other conflicts.

We view chat rooms as an additional tool available for subject material instruction. The medium brings unique advantages, as well as disadvantages, to the educational process.

\section{Literature cited}

Betzold, J. 1998. Chat rooms-Safety and security measures. B ehavioral $\mathrm{H}$ ealth $\mathrm{M}$ gt. 18(6):12.

H eid, J. 1998. Liven up your site with chats and conferences. M acworld 15(3):115-118.

Jackson, C., B. Yorker, and P. M itchem. 1996. Teaching cultural diversity in a virtual classroom. J. C hild A dolescent P sychiatric N ursing 9(4):40-42.

Pritchard, C.L. 1998. From classroom to chat room. Training D ev. 52(6):76-77. 